\title{
A multifacetária legitimidade da Soft Law \\ e o caso do Guiding Principles \\ on Internal Displacement
}

\author{
The Multiple Legitimacy of Soft Law \\ and the Case of the Guiding Principles \\ on Internal Displacement
}

\section{La légitimité multiforme du Soft Law et le cas du Guiding principles du déplacement d'internet}

\section{Rodrigo Lobato Oliveira de Souza*}

\begin{abstract}
SUMÁRIO: I. Introdução. II. Elementos para a (re)construção da legitimidade da Soft Law pelo movimento plural e difuso. III. Case Study: The Guiding Principles on Internal Displacement como Soft Law. Fundamentos, influência e força normativa. IV. Conclusão. V. Bibliografia.
\end{abstract}

* Universidade Autónoma de Lisboa, Brasil; ORCID ID: https: / /orcid.org/0000-0001-87 20-1996,rodrigolbt.advogado@gmail.com. 
Resumo: O presente texto possui como ponto central o estudo da Soft Law como novo paradigma do cenário jurídico-normativo internacional, tratando especificamente do Guiding Principles on Internal Displacement como documento direcionado ao estabelecimento de padrões mínimos para a proteção dos deslocados internos (internally displaced persons), bem como a prevenção e solução dos problemas relativos ao internal displacement. Sustentando-se a tese de que tal documento constitui uma verdadeira "Constituição do subsistema parcial dos internally displaced”, analisa-o sob a ótica da Global Governance e do Transconstitucionalismo, defendendo, assim, sua normatividade, juridicidade e legitimidade plural e difusa.

Palavras-chave: Soft Law, direitos humanos, governança, transconstitucionalismo.

ABSTRACT: This text has as central point the study of Soft Law as a new paradigm of international legal-normative scenario, dealing specifically with the Guiding Principles on Internal Displacement as a document directed to the establishment of minimum standards for the protection of idps (internally displaced persons), as well as the prevention and solution of problems related to internal displacement. Supporting the thesis that this document constitutes a genuine "Constitution of the partial subsystem of internally displaced", parses it under the perspective of the Global Governance and the Trans-Constitutionalism, defending their normativity, juridicity and their plural and diffuse legitimacy.

Key words: Soft Law, human rights, governance, trans-constitutionalism.

RÉSUMÉ: Le présent texte a pour point central l'étude du Soft Law comme un nouveau paradigme du scénario juridique-normatif international, traitant spécifiquement des principes directeurs sur les déplacements internes en tant que document visant à établir des normes Pour la protection des personnes déplacées à l'intérieur du marché (personnes déplacées), ainsi que la prévention et le règlement des problèmes liés aux déplacements internes. Soutenant la thèse que ce document constitue une véritable «constitution du sous-système partiel des déplacés internes», l'analyse du point de vue de la gouvernance mondiale et du Transconstitutionnalisme, défendant ainsi sa normativité, sa juridicité et Légitimité plurielle et diffuse.

Mots-clés: Soft Law, droits de l'homme, la gouvernance, transconstitutionnalisme. 


\section{INTRODUÇÃO}

Perfaz-se inconteste que o fator globalização tem paulatinamente arrefecido a hermética compreensão da autodeterminação político-institucional dos Estados. ${ }^{1} \mathrm{O}$ surgimento de novas problemáticas de manifesta dimensão glo$\mathrm{bal}^{2}$ tem cada vez mais pressionado a sociedade moderna a adotar uma adequada e eficaz responsividade mediante o diálogo coordenado entre distintos ordenamentos jurídico-políticos. Questões relativas à proteção universal dos direitos humanos, ao tratamento jurídico-penal e político-penal das organizações criminosas internacionais e transnacionais, o enquadramento jurídico-político relativo ao desenvolvimento e armazenamento de armamento nuclear, bem como a problemática concernente às alterações climáticas, dada a sua afetação global, não podem se quedar restritas ao tratamento endereçado pelos respectivos ordenamentos jurídicos dos Estados, devendo, portanto, se submeter ao espectro regulatório do Direito Internacional.

Da perspectiva jurídico-internacional, a adequação regulatória de temáticas que lhe são afetas não se dá da mesma forma e proporção que no âmbito do direito interno dos Estados, pois ao invés de se submeterem a uma estrita vinculação ao princípio da legalidade como expressão do princípio do Estado de Direito (Rechtstaatsprinzip) $)^{3}$ e às lindes do exercício da soberania estatal, o produto do processo decisório deve ser alcançado por meio de amplos diálogos institucionais destinados ao atingimento de um consenso ótimo, de toda forma sujeito ao princípio geral do pacta sunt servanda. ${ }^{4}$ Conquanto, ainda

1 Garcia, Frank J., "Introduction: Globalization, Power, States, and the Role of Law”, Boston College Law Review, Massachusetts, vol. 54, núm. 3, art. 3, 2013, p. 904. Afirmando que, ao menos em alguns aspectos, o processo de globalização tornou os Estados enfraquecidos frente às forças globais.

2 Ibidem, pp. 904 e 905. Afirma que um dos principais impactos da globalização está na revolução dos processos de telecomunicação, eliminando óbices como o tempo e espaço no âmbito das relações interpessoais, tornando, portanto, nenhuma região ou país imune a problemas relativos à prática de crimes em massa, à propagação do terror, bem como os efeitos nefastos de conflitos regionais.

3 Para um conceito geral de Estado de Direito, cfr. Hesse, Konrad, Grundzüge desVerfassungsrechts der Bundesrepublik Deutschland, 20a. ed., Heidelberg, C. F. Müller Verlag, 1999, pp. 86 e 87.

4 De acordo com Granoff, Jonathan, "Pacta Sunt Servanda: Nuclear Weapons and Global Secure Sustainable Development”, Southwestern Journal of International Law, California, vol. 
assim o produto normativo do processo decisório em âmbito internacional carece de ratificação perante a ordem interna dos Estados, condicionando-se a específicos e distintos processos legislativos.

Neste sentido, a problemática de partida subjacente à análise que ora se pretende decorre do confronto entre a irrefutável emergência de novos desafios regulatórios para o Direito Internacional e o condicionamento do produto dos seus processos de tomada de decisão a procedimentos internos dos Estados, que em sua grande maioria são excessivamente burocráticos, padecendo a responsividade internacional às novas problemáticas de reduzida efetividade. Assim sendo, questiona-se se as fontes (clássicas) do Direito Internacional apontadas pelo art. 38 do Estatuto da Corte Internacional de Justiça $^{5}$ (convenções internacionais, costume internacional, princípios gerais do direito, opiniões jurídicas e decisões judiciais) são as únicas possíveis e suficientes ao enfrentamento de todas as questões regulatórias de cariz internacional ou se têm os Estados se utilizado de outras, notadamente em vista à dinamicidade do cenário político-social.

Em resposta não exauriente ao questionamento anterior, a doutrina tem apontado para a insuficiência do rol descrito no pórtico do art. 38 do Estatuto da CIJ, ${ }^{6}$ demonstrando o recrudescimento do manejo de instrumentos regulatórios outros ali não previstos, ${ }^{7}$ entretanto mais céleres, eficientes e responsivos aos novos problemas e desafios de ordem global ${ }^{8}$. Nesse processo evolutivo-regulatório do Direito Internacional e suas fontes, a doutrina passou a distinguir entre aqueles elementos normativos de natureza vinculante (hard) e os de natureza a princípio não-vinculante

21, núm. 2, marzo-mayo de 2015, pp. 311 e 312. A máxima pacta sunt servanda é o elemento normativo responsável por assegurar segurança jurídica e estabilidade internacional.

5 Statute of the International Court of Justice, disponível em: https: / /www.icj-cij.org/ en/statute.

6 Apontando a referida insuficiência, ao menos no âmbito da proteção dos direitos humanos, cfr. Olivier, Michèle, "The relevance of «soft law» as source of international human rights", The Comparative and International Law Journal of Southern Africa, Southern Africa, vol. 35, núm. 3, 2002, p. 289.

7 Hillgenberg, Hartmut, “A Fresh Look at Soft Law”, European Journal of International Law, Oxford, vol. 10, núm. 3, 1999, p. 499.

8 Neste sentido, cfr. Garcia, Frank J., op. cit., p. 909. Aduzindo que o processo de globalização tem provocado profundas alterações no papel regulatório do Direito e seus instrumentos, provocando inclusive o surgimento de novas formas de governança para fins de adaptação aos novos desafios globais. 
Esta revista forma parte del acervo de la Biblioteca Jurídica Virtual del Instituto de Investigaciones Jurídicas de la UNAM

(soft). ${ }^{9}$ Dentre os novos instrumentais manejados pelos Estados no contexto internacional, pode-se referenciar os acordos políticos, recomendações, resoluções emitidas por organizações internacionais governamentais ou não-governamentais, linhas-guia e princípios, ${ }^{10}$ todos reconduzidos à categoria doutrinária compreendida sob o significante Soft Law, ${ }^{11}$ cuja principal característica apontada é a sua (suposta) não-vinculatividade. ${ }^{12}$

No que tange ao conceito de Soft Law, Steven A. Kennett aponta três formas básicas de compreensão: a primeira, como "pré-direito" (pre-law), onde normas e princípios emergentes são adotados como pontos de base ao tratamento de determinada problemática; segundo, pode designar um conjunto de regras que, a despeito de não vinculantes, são dotadas de um status jurídico capaz de influenciar diretamente o Direito Internacional como um todo; e terceiro, pode indicar uma fase transitória do processo regulatório onde as normas, assumindo uma estrutura aberta e genérica, constituem um parâmetro jurídico mínimo para a posterior elaboração de normas mais específicas e vinculantes, ${ }^{13}$ razão pela qual Gregory C. Shaffer e Mark A. Pollack salientam que Hard Law e Soft Law muitas das vezes podem assumir funções complementares. ${ }^{14}$

Por um lado, a ideia subjacente ao significante Soft Law acaba por encerrar um certo contrassenso, ${ }^{15}$ posto que a compreensão de um "Quase-direito",

9 Kennedy, David, "The Sources of International Law", American University International Law Review, Washington, vol. 2, núm. 1, art. 1, 1987, p. 20.

10 Williamson, Richard L. Jr., "Hard Law, Soft Law and Non-Law in Multilateral Arms Control: Some Compliance Hypotheses”, Chicago Journal of International Law, Chicago, vol. 4, núm. 1, art. 7, abril de 2003, p. 63.

11 Cárdenas Castañeda, Fabián Augusto, "A Call for Rethinking the Sources of International Law: Soft Law and the other Side of the Coin”, Anuario Mexicano de Derecho Internacional, México, vol. XIII, 2013, p. 372.

12 Cfr. Di Robilant, Anna, "Genealogies of Soft Law", The American Journal of Comparative Law, Oxford, vol. 54, núm. 3, julio de 2006, p. 499-554.

13 Kennett, Steven A., "Hard Law, Soft Law and Diplomacy: The Emerging Paradigm for Intergovernmental Cooperation in Environmental Assessment”, Alberta Law Review, Alberta, vol. 31, núm. 4, pp. 646 e 647.

14 Schaffer, Gregory C. e Pollack, Mark A., "Hard versus Soft Law in International Law Security”, Boston College Law Review, Massachusetts, vol. 52, núm. 4, art. 1, 2011, p. 1156.

15 Para críticas ao termo Soft Law, cfr. Lichtenstein, Cynthia C., "Hard Law v. Soft Law: Unnecessary Dichotomy?", The International Lawyer, Chicago, vol. 35, núm. 4, diciembre-febrero de 2001, p. 1433. Ainda, sobre o paradoxo conceitual, cfr. Ferris, Elizabeth e Bergmann, Jonnas, "Soft Law, Migration and Climate Change Governance", Journal of Human Rights and Environment, Cheltenham, vol. 8, núm. 1, marzo de 2017, p. 12. 
cujos instrumentos são desprovidos de força vinculante (elemento obrigacional primário), apresenta-se contrária à indispensável coercitividade do Direito como um todo. De outra banda, a operacionalização de instrumentos de Soft Law decorre do processo de evolução das relações internacionais frente à complexidade e dinamicidade dos emergentes desafios e problemas que se colocam à resolução ao nível global. Conquanto a operacionalização de instrumentos soft para o tratamento de determinadas matérias seja de fato útil e minimamente eficaz, notadamente por evitar o esvaziamento regulatório internacional no âmbito do processo interno e excessivamente burocrático dos Estados, o seu crescente manejo tem suscitado o questionamento da própria legitimidade do Direito Internacional. Ladeando o fator globalização, a evolução do tratamento normativo na ordem internacional passou por um processo de descentralização, não apenas pelo manejo de instrumentos normativos soft, mas porque a sua utilização passou igualmente às mãos de atores não-estatais (por exemplo, organizações não-governamentais) com evidente reflexos sobre questões de indelével relevância, como a proteção de direitos fundamentais reconhecidos pela ordem constitucional dos Estados.

Isto posto, a presente investigação traz à lume discussões sobre as formas de (re)construção da legitimidade dos instrumentos de Soft Law no âmbito jurídico internacional, encetando a tese de que, a partir da perspectiva da Governança Global e do Transconstitucionalismo, é possível reconduzirmos elementos soft ao enquadramento das fontes jurídico-normativas do Direito Internacional. Desta feita, na Parte II serão oferecidos e analisados os elementos de base para a fundamentação da legitimidade normativa dos instrumentos de Soft Law; na Parte III, alguns aspectos do Guiding Principles on Internal Displacement serão discutidos como estudo de caso; apresentando-se por fim, na Parte IV, os argumentos de fecho à defendida legitimidade da Soft Law como fonte normativa legítima do Direito Internacional.

\section{ElEMENTOS PARA A (RE)CONSTRUÇÃO DA LEGITIMIDADE DA SOFT LAW PELO MOVIMENTO PLURAL E DIFUSO}

De início, deve-se salientar a característica "temperada" da normatividade do Direito Internacional. Excluída a submissão a uma normatividade estri- 
ta, centrada no elemento da "estatalidade" (esfera pública estatal), o processo regulatório-decisório do Direito Internacional deve ser compreendido sob a perspectiva da dinamicidade e da pluralidade dos ordenamentos jurídicos imbricados. Para que se proceda à análise e a defesa da legitimação plural e difusa da Soft Law (algo que se opera tanto pelo discurso quanto pelo intercâmbio material-normativo), serão utilizados como topoi: a interculturalidade, a intersemioticidade e a interconstitucionalidade.

No contexto de uma pluralidade de culturas constitucionais envolvidas no processo regulatório-decisório internacional, há que se buscar mecanismos operacionais para o estabelecimento de um diálogo adequado para fins de atingimento de uma comunicabilidade material entre sistemas de distintas feições normativas. Neste desiderato, os topoi acima referidos visam, em atuação conjunta, a compreensão de diferentes ordens jurídico-políticas no contexto de um processo de Transconstitucionalismo, cada qual dotado de funcionalidade voltada à estabilização de elementos constitucionais variados ao nível do processo regulatório-decisório de âmbito internacional.

O topos interculturalidade. No contexto de uma ambiência sócio-política permeada por distintos fundamentos culturais, a interculturalidade aponta para a necessidade de se estabelecer uma relação empática entre topoi culturais inicialmente não comunicáveis. Para que tal diálogo seja viabilizado, faz-se necessária a operacionalização de um método hermenêutico diatópico, ${ }^{16}$ através do qual a observação e compreensão "do outro" (topoi culturais alheios), deve-se partir da neutralização do ponto de vista "original” do observador, a fim de que de simples objeto cognoscível, o alter (material cultural "do outro") se torne igual sujeito cognoscente. A interculturalidade surge, em verdade, como uma nova abordagem à integração sócio-política, assumindo que, dada a fragmentária e mutável noção de identidade cultural da sociedade moderna, os distintos elementos

16 No que tange à hermenêutica diatópica, Sousa Santos, Boaventura de, "Toward a Multicultural Conception of Human Rights”, en Hernández-Truyol, Berta (ed.), Moral Imperialism. A Critical Anthology, New York University Press, 2002, pp. 47 e 48. Argumenta ser indispensável, como ponto de partida para qualquer diálogo intercultural, o reconhecimento da "incompletude" tanto do sistema étnico-cultural observador quanto do sistema observando, caso contrário a mera imposição de fortes topoi culturais sobre um sistema alheio tornaria qualquer comunicação inviável, além de provocar severos conflitos, desintegração social e estigmatização. 
culturais devem ser reconhecidos sob o vetor da igual dignidade, promovendo-se um diálogo voltado à resolução de possíveis incompatibilidade. ${ }^{17}$ De acordo com Shkelzen Hasanaj, a interculturalidade deve ser compreendida em quatro elementos básicos: primeiro, a diversidade, reconhecendo-se, como base do diálogo intentado, que as distintas nações são compostas como uma coletividade de indivíduos, cujas origens étnicas e culturais são diversas; segundo, a homogeneidade, pela qual se deve compreender que os distintos grupos culturais e étnicos são iguais em dignidade; terceiro, a multipolaridade, reconhecendo-se que em um mesmo território coexistem diversos grupos sociais; e quarto, a dualidade, que o igual reconhecimento distintos grupos étnico-culturais deve se conferido tanto para as maiorias quanto para as minorias. ${ }^{18}$

$O$ topos intersemioticidade. A intersemioticidade expressa o fluxo comunicacional e a dinamicidade de intercâmbios de símbolos jurídicos (teorias, discursos, argumentos, elementos normativos) de distintas culturas sócio-políticas. Pela interconexão semiótica, diferentes ordenamentos jurídicos buscam a irrigação material de seus respectivos sistemas através da assimilação recíproca, ainda que temperada, de expressões jurídico-normativas alheias. ${ }^{19}$ Assim, doutrinas, argumentos jurídicos, fundamentações teóricas e até mesmo decisões judiciais pertencentes a outros ordenamentos jurídicos são elementos assumidos como materiais de trabalho de um dado sistema, encetando-se, assim, um diálogo material entre ordens originalmente tidas por estanques. ${ }^{20} \mathrm{~A}$ título de exemplificação, o discurso jurídico dos direitos humanos pode ser compreendido sob tal perspectiva intersemiótica, uma vez que a linguagem normativa comumente manejada na matéria, ape-

17 Hasanaj, Shkelzen, "Multiculturalism vs. Interculturalism: New Paradigm? (Sociologic and Juridical Aspects of the Debate between the two Paradigms)?", Journal of Education \& Social Policy, Nueva York, vol. 4, núm. 2, junio de 2017, pp. 171-177.

18 Ibidem, p. 176.

19 Neste sentido, Barroso, Luís Roberto, "Here, There, and Everywhere: Human Dignity in Contemporary Law and in the Transnational Discourse”, Boston College International \& Comparative Law Review, Massachusetts, vol. 35, núm. 2, art. 2, 2012, p. 344. Afirma que a formação de novas democracias levou à busca pela troca de novas informações e perspectivas, notadamente no intuito de se atingir um possível consenso no âmbito do discurso jurídico transnacional.

20 Balkin, J. M., "The Hohfeldian Approach to Law and Semiotics”, University of Miami Law Review, Florida, vol. 44, núm. 5, 1990, p. 1138. Ressalta a importância do estudo semiótico do discurso jurídico como forma de compreensão da linguagem utilizada por determinada cultura jurídica e da ideologia que lhe é subjacente. 
sar de abarcar especificidades de cada ordenamento jurídico estatal, opera a partir de um diálogo intercultural de símbolos jurídicos assentados sob o denominador axiológico da "dignidade humana". ${ }^{21}$

$O$ topos interconstitucionalidade. ${ }^{22}$ De início, há que se salientar que a interconstitucionalidade constitui reflexo direto da conjugação topoi anteriormente referidos, ou seja, constitui produto da atuação conjunta dos elementos de "interculturalidade" 23 e "intersemioticidade". Em breve guisa de conceituação, a interconstitucionalidade expressa o fenômeno pelo qual distintas ordens jurídico-constitucionais realizam o intercâmbio de materiais constitucionais de variada natureza, emergindo deste processo uma linguagem ou discurso transnacional sobre matéria constitucional, ao que se pode referenciar, como exemplo, as cláusulas do "Estado de Direito", "Estado Social”, "Estado Constitucional Democrático", "democracia”, “controle de constitucionalidade das leis", "separação de poderes”, "direitos, liberdades e garantias constitucionais", dentre outros elementos. ${ }^{24} \mathrm{O}$ intercâmbio de elementos da "cultura constitucional" (interculturalidade) ${ }^{25} \mathrm{e}$ de "textos normativos" (intersemioticidade) ${ }^{26}$ constituem, simultaneamente, o material intercambiável e a condição de procedibilidade ao diálogo transconstitucional, permitindo a observação, a análise e a apreensão de experiências diversas, uma vez que os textos constitucionais se encontram cada vez mais em diversos níveis de conexão. ${ }^{27}$

21 Sobre um consenso acerca do conteúdo mínimo do conceito de dignidade humana, $c f r$. McCrudden, Christopher, "Human Dignity and Judicial Interpretation of Human Rights", The European Journal of International Law, Oxford, vol 19, núm. 4, 2008, 679 e 680.

22 Para uma teoria da interconstitucionalidade, $c f r$. Canotilho, J. J. Gomes, Direito constitucional e teoria da Constituição, 7a. ed., Coimbra, Almedina, 2003, pp. 1425 e ss.

23 Neste sentido, Rocha, Leonel Severo e Tonet, Fernando, "A interconstitucionalidade como produção jurídica descentralizada dentro de novas observações estatais”, Revista Brasileira de Estudos Políticos, Belo Horizonte, núm. 115, julio-diciembre de 2017, p. 481. Afirmam: "A teoria da interconstitucionalidade só é possível através da junção de culturas".

${ }^{24}$ É neste sentido que Barroso, Luís Roberto, op. cit., p. 343. Afirma ocorrer a recíproca citação de decisões judiciais de ordem constitucional no contexto de um amplo diálogo institucional.

25 Canotilho, J. J. Gomes, Direito constitucional..., cit., pp. 1427 e 1428.

26 Ibidem, pp. 1429 e 1430.

27 Rocha, Leonel Severo e Tonet, Fernando, op. cit., p. 479. "Quando esses mecanismos sistêmicos se unem e dialogam entre si, criam um ambiente de interorganização sistêmica, que é possível graças à autonomia de cada organização”. 
Referenciados os topoi acima, questiona-se: qual a conexão existente entre tais elementos, o Direito Internacional, e a necessidade de legitimação dos instrumentos de Soft Law?

Os topoi "interculturalidade", "intersemioticidade" e "interconstitucionalidade" constituem os elementos-amálgama que tornam possível o intercâmbio de materiais normativos entre distintos ordenamentos jurídico-políticos no processo regulatório-decisório em âmbito internacional, cuja operacionalização permite o estabelecimento de um amplo diálogo intersistêmico. Em breve excurso, vejamos a operacionalização destes topoi. Pela interculturalidade, a regulação normativa na ordem internacional deve levar em consideração todos os aspectos, elementos, perspectivas e reflexos culturais dos Estados envolvidos no processo; ${ }^{28}$ pela intersemioticidade, o processo regulatório-decisório deve se quedar aberto ao influxo dos materiais normativos (textos de norma, decisões, doutrinas, argumentos, discursos e teorias) dos distintos ordenamentos jurídico-políticos dos Estados; por fim, pela interconstitucionalidade, a conexão, justaposição ou aglutinação de dados constitucionais variados impulsiona a crescente inserção de elementos constitucionais (direitos, bens, valores e interesses) em instrumentos de Direito Internacional. ${ }^{29}$

Da mesma forma que a operacionalização conjunta dos topoi "interculturalidade" e "intersemioticidade" tornam viável a funcionalização do topos "interconstitucionalidade", é através deste último que o processo de transconstitucionalidade se torna possibilitado no contexto global de uma rede de Constituições em ampla intercomunicação. Neste sentido, é de se colocar o seguinte questionamento: como este processo de transconstitucionalidade afeta a legitimidade dos instrumentos de Soft Law? O Transconsti-

28 O tratamento do proselitismo no âmbito do Direito Internacional é um excelente exemplo de interculturalidade. Quando da elaboração da Declaração Universal de Direitos Humanos de 1948, a Arábia Saudita, no que concerne ao reconhecimento do "direito de mudar a religião ou a crença de outro", suscitou reservas ao texto elaborado, notadamente por conflitar com a problemática da apostasia no mundo islâmico. Para tanto, cfr. Hirsch, Moshe, "The Freedom of Proselytism under the Fundamental Agreement and International Law", Catholic University Law Review, Washington, vol. 47, núm. 2, art. 6, diciembre-febrero de 1998, p. 412.

29 Neste sentido, Mayer, Ann Elizabeth, "Universal versus Islamic Human Rights: A Clash of Cultures or a Clash with a Construct?", Michigan Journal of International Law, Michigan, vol. 15, núm. 2, 1994, p. 328. Afirma, como exemplo, que a Declaração do Cairo sobre Direitos Humanos, assumiu elementos discursivos constantes da inúmeras outras Declarações de Direitos no contexto internacional, aglutinando-os a elementos da cultura islâmica, em evidente processo de interculturalidade e de intersemioticidade. 
Esta revista forma parte del acervo de la Biblioteca Jurídica Virtual del Instituto de Investigaciones Jurídicas de la UNAM

tucionalismo é aqui manejado como recurso parcial discursivo para fins de fundamentação da legitimação da Soft Law. A transversalidade constitucional dos instrumentos de direito internacional hard e soft, bem como destes para com inúmeras ordens jurídico-constitucionais, cuja operacionalização é voltada para a proteção, direta ou indireta, de valores e elementos constitucionais diversos, torna a abordagem de sua legitimidade pelo discurso constitucional necessária e igualmente desejável.

A ideia de "transconstitucionalismo" implica uma complexa série de elementos estruturais cujo ponto comum é representado pelo direcionamento e pela funcionalização de todo o conteúdo constitucional, apreendido e apreensível, com vistas à resolução de problemas constitucionais enfrentados em distintos níveis, ${ }^{30}$ tais como os de ordem internacional, transnacional, supranacional e/ou regional. ${ }^{31}$ Como background político-social, tem-se o processo de globalização como uma das principais causas do deslocamento do enfrentamento de problemas constitucionais a partir de uma perspectiva meramente de "estatalidade", para uma perspectiva além-fronteiras, ${ }^{32}$ da transnacionalidade e da globalidade. ${ }^{33}$

30 Neves, Marcelo, Transconstitucionalismo, São Paulo, Editora WMF Martins Fontes, 2009, p. XXI.

31 Neste sentido, Vandresen, Thaís e Antunes de Souza, Maria Cláudia S., "Globalization, Global Governance, and Challenges to Contemporary Constitutionalism: The (trans) Constitutional Respective and the Dialogue among Jurisdictions", University of Baltimore Journal of International Law, Baltimore, vol. 4, núm. 2, art. 2, 2015-2016, p. 20, oferecem como exemplo o sistema interamericano de proteção dos direitos humanos no contexto do diálogo entre os direitos reconhecidos pela Convenção Interamericana e as respectivas ordens constitucionais dos Estados-signatários.

32 Partindo do reconhecimento da necessidade de ampliação do espectro de tratamento jurídico de novas problemáticas sociais, políticas e jurídicas, Neves, Marcelo, "Do diálogo entre as cortes supremas e a Corte Interamericana de Direitos Humanos ao transconstitucionalismo na América Latina”, Revista de Informação Legislativa, Brasília, año 51, núm. 201, 2014, p. 194. Afirma que o transconstitucionalismo "aponta para o fato de que surgem cada vez mais questões que poderão envolver instâncias estatais, internacionais, supranacionais e transnacionais (arbitrais), assim como instituições jurídicas locais nativas, nas busca da solução de problemas tipicamente constitucionais".

33 Neste sentido, Peters, Anne, "The Merits of Global Constitutionalism”, Indiana Journal of Global Legal Studies, Indiana, vol. 16, núm. 2, junio-agosto de 2009, pp. 405 e 406, defende o manejo do conceito de Constitucionalismo Global como um recurso hermenêutico no contexto regulatório-decisório internacional, buscando a sua legitimidade pela força do material constitucional que carregam, notadamente pela proteção que visam conferir a direitos, bens, valores e interesses de cunho jurídico-constitucional. 
O espectro de proteção oferecido no contexto do constitucionalismo liberal sob os elementos da legitimidade democrática, controle e limitação do poder estatal, ${ }^{34}$ tem sofrido patente pressão sob os novos desafios engendrados pela constante mutação da Ciência jurídico-constitucional ${ }^{35}$ frente ao processo de globalização. ${ }^{36}$ Tendências mundiais como os movimentos de digitalização, privatização e conexão global evidenciam a necessidade de uma resposta coordenada entre ordens jurídicas diversas, notadamente um amplo entrelaçamento de matérias e problemas constitucionais há de ocorrer.

As dificuldades operacionais num contexto global impedem, ou ao menos tornam menos efetivas, as ações responsivas isoladas das respectivas ordens jurídico-constitucionais dos Estados. Mesmo ao nível jurídico-internacional, o endereçamento de problemáticas emergentes, e de afetação global, unicamente pela perspectiva de instrumentos normativos clássicos do Direito Internacional Público (Hard Law) não tem sido o suficiente. A perspectiva jurídico-internacional restrita e centralizada no elemento da "estatalidade" do Direito Internacional não é mais capaz de resolver questões manifestamente transversais ${ }^{37}$ a todas sociedades. Como consequência, a falta, a ineficiência e/ou inefetividade regulatória sobre diversos âmbitos da vida social acabam por exigir uma responsividade paralela àquela das ordens constitucionais dos Estados, e igualmente

34 Neste sentido, Teubner, Günther, "Globale Zivilverfassungen: Alternativen zur staatszentrierten Verfassungstheorie”, Zeitschrift für Ausländisches Öffentliches Recht und Völkerrecht, Heidelberg, núm. 63, 2003, p. 5. Ressalta a concepção conservadora da Teoria da Constituição quanto à função das Constituições como documento fundante e regulador do espectro jurídico-político do Estado.

$35 \mathrm{Na}$ esteira de tais desafios, suscita a doutrina a problematização quanto à construção de um "constitucionalismo sem Estado". Neste sentido, Canotilho, J. J. Gomes, "Brancosos" e interconstitucionalidade: itinerários dos discursos sobre a historicidade constitucional, 2a. ed., Coimbra, Almedina, 2008, p. 288.

36 Teubner, Günther, “Globale Zivilverfassungen...”, cit., p. 11. Afirma que a globalização representa o movimento de emancipação de grupos e âmbitos sociais de vida para além de suas respectivas regiões, auferindo-lhes considerável autonomia.

37 No sentido de problemas que afetam a sociedade mundial por completo, seja de forma simultânea ou não, são consideradas "transversais" as questões relacionadas a direitos fundamentais e direitos humanos que suscitam discussões acerca de possíveis intervenções entre Estados; a regulação sobre o desenvolvimento de projetos que possam afetar o meio ambiente; a regulação sobre a posse e produção de armas nucleares; a prevenção e combate às consequências de alterações climáticas, dentre outras. 
Esta revista forma parte del acervo de la Biblioteca Jurídica Virtual del Instituto de Investigaciones Jurídicas de la UNAM

paralela ao tratamento sob o Direito Internacional pela perspectiva da Hard Law, identificando-se, assim, o surgimento de movimentos difusos de autorregulação, ${ }^{38}$ tanto por parte de atores estatais, como por parte de atores não estatais. ${ }^{39}$

Neste ponto, releva compreender que não se trata apenas de uma regulação supletiva por parte de atores diretamente ligados aos respectivos setores sociais, mas sim do reconhecimento de todo um background jurídico-regulatório institucional já existente, no sentido de que a cada setor corresponde uma pletora de regras próprias - na esteira da lex mercatoria e da lex digitalis - paulatinamente mais responsáveis pelo movimento de autonomização regulatória de tais âmbitos. ${ }^{40}$ Assim, impende-se reconhecer que não mais apenas os centros estatais e interestatais do Poder são capazes e aptos a produzir “direito", mas também o são os âmbitos e setores cada vez mais autônomos da sociedade, ainda que ambos processos de produção normativa sejam consideravelmente distintos.

Sob tal quadrante, Günther Teubner defende que tais setores autônomos acabam por ser identificados e legitimados por um subsistema constitucional parcial, como se a cada um correspondesse uma "Constituição Civil"

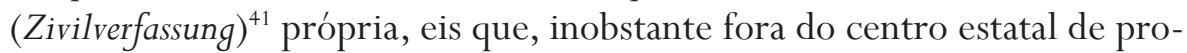
dução jurídico-normativa, são reconduzidos a processos próprios de organização sistêmica, legitimação e controle. ${ }^{42}$ Nessa linha, deveras discutido na doutrina é a questão do reconhecimento de uma espécie de "Constitui-

38 No contexto regulatório da internet, Teubner, Günther, “Globale Zivilverfassungen...”, cit., p. 18. Chama atenção para o movimento de autorregulação deste setor.

39 A título de exemplificação, Berman, Paul Schiff, "From International Law to Law and Globalization”, Columbia Journal of Transnational Law, Nueva York, vol. 43, núm. 2, 2005, p. 547. Aponta para o papel cada vez mais ativo e amplo de instituições não-governamentais, contribuindo diretamente para a formação de parâmetros globais de comportamento corporativo.

40 Como exemplo, Teubner, Günther, “Global Private Regimes: Neo-Spontaneous Law and Dual Constitution of Autonomous Sectors in World Society?”, en Ladeur, Karl-Heinz (ed.), Globalization and Public Governance, Aldershot, Ashgate Publishing, 2004, p. 72. Cita como âmbitos sociais autorreguláveis a ciência, a tecnologia, a educação, a economia e os mass media.

41 Teubner, Günther, “Globale Zivilverfassungen...”, cit., p. 6.

42 Para utilizar a linguagem e o discurso jurídico-constitucional em defesa de tais "Constituições Civis parciais”, Teubner, Günther, "Globale Zivilverfassungen...”, cit., pp. 3 e 5. Defende que um dos erros da tradicional Teoria da Constituição se encontra na restrição de seu espaço ao âmbito estatal-interno. 
ção Econômica Global”³ sob o contexto regulatório da Organização Mundial do Comércio (WTO - World Trade Organization), seja pela previsão de assuntos de cunho jurídico-constitucional, pela estrutura institucionalizada que em tese encetou, pela praxis prevista para a resolução de confli$\operatorname{tos}^{44}$ ou mesmo pela conjugação de todos esses elementos. Para Deborah Z. Cass, o processo de "constitucionalização" da regulação do comércio internacional está centrado na sua capacidade de gerar "normas" de cunho constitucional, em especial através do processo hermenêutico aplicado no âmbito da resolução de conflitos levada a cabo pelo órgão de revisão de disputas da OMC. ${ }^{45}$ Destarte, a linguagem teorético-jurídica do Direito passa a considerar os subsistemas sociais autônomos que emergem do processo de descentralização da produção jurídico-normativa, cada vez mais legitimados de facto à regulação numa sociedade dinâmica como a globalizada e de governança multinível.

Conceito relevante nessa perspectiva de descentralização e ampliação regulatória é o de governança global (Global Governance), ${ }^{46}$ a partir do qual passa-se a reconhecer que, dada a auto-expansividade dos diversos subsistemas sociais e de seus respectivos âmbitos de autorregulação, urge a aplicação de uma abordagem político-administrativa não mais restrita à figura do Estado, mas antes uma abordagem estruturada sob uma compreensão que abarque a produtividade e a efetividade das respectivas forças normativo-regulatórias autônomas, integrando-as a uma ampla esfera de "publicidade" institucional. Em termos regulatórios - para não dizer "legislativos" -, a figura central do Estado, bem como as relações interestatais ao nível do Direito Internacional, não mais são as únicas que contribuem para o surgimento de normas, sendo igualmente capazes de atuar de forma legiferante atores do setor privado, atores estes não-estatais, ainda que de forma difusa

43 Dunoff, Jeffrey L., “Constitutional Conceits: The WTO's «Constitution» and the Discipline of International Law”, European Journal of International Law, Oxford, vol. 17, núm. 3, 2006, p. 651.

44 Ibidem, pp. 655-657.

45 Cass, Deborah Z., "The Constitutionalization of International Trade Law: Judicial Norm-Generation as the Engine of Constitutional Development in International Trade”, European Journal of International Law, Oxford, vol. 12, núm. 1, 2001, pp. 41-42.

46 Sobre Global Governance, cfr. Blahoz, Joseph, "The Theory of Global Governance, Constitutionalization and Comparative Constitutional Law", The Lawyer Quarterly: International Journal for Legal Research, Praga, vol. 43, núm. 3, 2013, p. 200. 
Esta revista forma parte del acervo de la Biblioteca Jurídica Virtual del Instituto de Investigaciones Jurídicas de la UNAM

e descentralizada. Neste sentido, Paul Schiff Berman assevera ser necessário compreender o Direito para além o Estado, já que muitas das funções que lhe são originalmente afetas têm passado ao raio de competência de atores e instituições privadas. ${ }^{47}$ Assim, o Direito e o obsoleto simbolismo da "lei" abrem suas portas para novos discursos regulatórios, como os instrumentos normativos emergentes sob a categoria da Soft Law. ${ }^{48}$

Aliás, para tanto, reconhece a doutrina que a dualidade outrora consolidada (separação entre público/privado) deve ser superada, pois hoje o discurso global resta caracterizado pela múltipla influência de fatores sociais de ambas as procedências, sendo igualmente responsáveis sobre a governança (administração regulatória e decisória) de múltiplos âmbitos da vida político-social, como a economia, o meio ambiente, a tecnologia e os direitos humanos. ${ }^{49}$ A constante "erosão" da efetividade e da legitimidade do Direito Internacional, ${ }^{50} \mathrm{e}$ até mesmo do próprio constitucionalismo "estatal-centrista”, e a isso somada a necessidade de reconhecimento de um espectro global de governança, torna plausível, ao menos em termos argumentativos, a transposição de elementos constitucionais ao processo regulatório-decisório de âmbito internacional, supranacional, transnacional e global, buscando, assim, reerguer ou reconstruir a legitimação do discurso jurídico-público. Entretanto, para que essa reconstrução (discursiva) da legitimidade se torne possível, há que se alargar a compreensão sobre a composição subjetiva e material da esfera pública, buscando-se atingir a formação de uma nova "publicidade" institucional, ${ }^{11}$ onde se reconhece a capacidade de governança e a competência institucional tanto de entes e instituições públicas, como de agentes, instituições e organizações privadas. Em verdade, perscruta-se o reconhecimento de uma representação democrática a nível "além-Estado", integrando-se à composição subjetiva da esfera pública institucional a plura-

47 Berman, Paul Schiff, op. cit., p. 550.

48 Krisch, Nico, "Global Governance as Public Authority: an Introduction", International Journal of Constitutional Law, Oxford, vol. 10, núm. 4, octubre de 2012, p. 982.

49 Berman, Paul Schiff, op. cit., p. 522. Ressalta, nesta senda, que muitos instrumentos de Direito Internacional Público têm conferido poderes legislativos-normativos a atores privados.

50 Questionando a legitimidade do Direito Internacional no contexto do século XXI, $c f r$. Weiler, J. H. H., "The Geology of International Law. Governance, Democracy and Legitimacy”, Zeitschrift für Ausländisches Öffentliches Recht undVölkerrecht, Heidelberg, vol. 64, 2004, pp. 548-553.

51 Krisch, Nico, op. cit., p. 983. 
lidade e multidimensionalidade de atores envolvidos no processo de internacionalização e globalização constitucional, reforçando-se tanto os inputs quanto os outputs de legitimidade subjetiva e material. ${ }^{52}$

Assim, considerando as diversas forças públicas imbricadas no cenário regulatório-decisório global, cada qual contribuindo com seu respectivo material normativo (resoluções, declarações, acordos, tratados, convenções, pactos, linhas-princípio, recomendações etc.), com a instituição de múltiplas formas de resolução de conflitos (jurisdicionais e arbitrais), e com novos fóruns de administração de justiça (meios previstos pelos textos da OMC por exemplo), a descentralizada linguagem normativa do Direito Internacional torna-se legitimada pelo reconhecimento de um constante processo de Governança Global em níveis múltiplos de transconstitucionalidade. No que concerne especificamente à Soft Law e seus respectivos instrumentos (linhas-princípio, recomendações, acordos políticos, dentre outros), a sua legitimidade pode ser reconstruída por três perspectivas fundamentais: primeira, a legitimidade subjetiva é promovida pela plural participação que há em seu processo de formação, onde agentes institucionais públicos e privados tomam parte na sua discussão e elaboração $;^{53}$ segunda, partindo do reconhecimento de um amplo e disseminado processo de transconstitucionalidade, os instrumentos normativos soft promovem o reconhecimento, a proteção e o controle sobre a atuação institucional dos Estados em matéria de cariz jurídico-constitucional, como direitos humanos, meio ambiente e aspectos climáticos, e autodeterminação político-institucional, pelo que sua legitimidade é reconstruída pela matéria; ${ }^{54}$ e terceira, os instrumentos de Soft Law constituem elementos normativos integrantes de um amplo processo de Governança Global de múltiplos níveis, tornando-se, portanto, legítimos em razão do processo.

52 Dunoff, Jeffrey L., op. cit., p. 668.

53 Bogdandy, Armin von, "Demokratie, Globalisierung, Zukunft des Völkerrechts. Eine Bestandaufnahme", Zeitschrift für Ausländisches Öffentliches Recht und Völkerrecht, Heidelberg, vol. 63, 2003, p. 874. Afirma que a ampliação subjetiva da participação na tomada de decisões no contexto regulatório internacional é um dos fatores para a inserção de um conteúdo democrático na acepção cooperativa que o Direito Internacional tem tomado.

54 Neste sentindo, claro exemplo desse processo de transconstitucionalidade está na crescente utilização de instrumentos de Soft Law como recurso discursivo-legitimador das decisões de Tribunais Constitucionais, Supremas Cortes, Tribunais Internacionais, Tribunais arbitrais, dentre outros órgãos de administração da justiça e de resolução de conflitos. 
Desta feita, o processo de transconstitucionalidade (mediante a conjugação dos topoi interculturalidade, intersemioticidade e interconstitucionalidade) e o processo multinível de Governança Global constituem as categorias argumentativas voltadas à legitimação dos variados instrumentos de Soft Law manejados no âmbito regulatório-decisório de nível internacional-global, justificando-se sua força normativa, e assim rejeitando qualquer suposição quanto à caracterização de "não-direito" ou direito desprovido de normatividade. Ao invés de uma força normativa centrípeta restrita à figura do Estado e suas clássicas funções públicas, a nova "publicidade" institucional no âmbito do processo multinível de Governança Global nos demonstra a ampliação subjetiva e material pela qual o processo regulatório-decisório internacional-global foi sujeito frente ao fenômeno da globalização, razão pela qual se pode defender a legitimação dos instrumentos soft pela pluralidade subjetiva, material e processual, sendo igualmente idôneos a influenciar comportamentos e estabelecer expectativas de estabilização normativa.

III. CASE STUDY: THE GUIDING PRINCIPLES ON INTERNAL DISPLACEMENT COMO SOFT LAW. FUNDAMENTOS, INFLUÊNCIA E FORÇA NORMATIVA

O Guiding Principles on Internal Displacement representa um dos mais importantes enquadramentos jurídico-políticos acerca dos chamados "deslocados internos” (Internally Displaced Persons - IDP’s), pessoas que são obrigadas a evadirem de suas moradas ou região de moradia devido a problemas de ordem bélica (sejam guerras civis ou conflitos armados internos), discriminações e violações de direitos humanos (em razão de crença religiosa, ideologia política, raça, e/ou sexo), fatores climáticos (alterações drásticas de temperatura e/ou desastres naturais), bem como em razão de projetos de desenvolvimento e expansão social.

$\mathrm{Na}$ tarefa de conceituação dos IDP's, é de se ressaltar o fato de que o "movimento de evasão" ocorre dentro de seus respectivos países de origem, provocando um fluxo migratório interno (não imigratório), eis que as pessoas afetadas não ultrapassam fronteiras internacionais. Intentando a conceituação da categoria de “deslocados internos", Erin Mooney assevera 
haver dois elementos centrais a serem levados em consideração, quais sejam, a natureza involuntária do movimento de evasão e o fato de não haver cruzamento de fronteiras internacionais, permanecendo os IDP's em seu país de origem, transferindo-se apenas para locais distintos de sua região de morada ou habitação. ${ }^{55}$

A preocupação com os IDP's se dera, inicialmente, no contexto do tratamento jurídico-político dos refugiados, em uma espécie de proteção estendida à guisa da regulação encetada pela Convenção de Genebra sobre Refugiados de $1951,{ }^{56}$ notadamente no tocante ao seu status (art. 1o.). ${ }^{57}$ Em que pese o intentado tratamento sob a proteção estendida do status jurídico-político dos refugiados, logo se percebeu que tal espectro regulatório se quedava inócuo, uma vez que, dentre outras diferenças, a situação dos IDP's não gera o transpasse de fronteiras internacionais, tornando aquele instrumento convencional, além de outros tratados ou instrumentos internacionais similares não aplicáveis à problemática, ao menos inquinando-os de eficácia arrefecida. ${ }^{58}$

A distinção entre IDP's e refugiados é tão tênue que alguns ${ }^{59}$ defendem a existência de dois tipos de "deslocados", os "deslocados internos" e os refugiados, sendo estes inseridos na categoria de "deslocados" que ultrapassam fronteiras internacionais. Em que pesem as possíveis similitudes, foi ao final da década de 80 e início da década de 90 (final da Guerra Fria) quando se percebeu uma profunda lacuna em termos de enquadramento e efetividade normativa acerca do tratamento dos IDP's, ${ }^{60}$ suscitando, a

55 Mooney, Erin, “The Concept of Internal Displacement and the Case for Internally Displaced Persons as a Category of Concern”, Refugee Survey Quarterly, Oxford, vol. 24, núm. 3, septiembre de 2005, p. 10.

56 Convention and Protocol Relating to the Status of Refugees, Resolution 2198 (XXI), United Nations General Assembly, disponível em: https: //www.unhcr.org/3b66c2aa10.

57 Liao, Kuan-Wen, "International Protection for Internally Displaced Persons”, All Theses and Dissertations, Washington University Open Scholarship, enero de 2009, pp. 1-85, disponível em: https: / /openscholarship. wustl.edu /cgi / viewcontent.cgi?article $=1471$ \&context $=$ etd.

58 Cohen, Roberta, “The Guiding Principles on Internal Displacement: An Innovation in International Standard Setting”, Global Governance, Utah, núm. 10, 2004, p. 459.

59 Jörnrud, Martin, "International Protection of Internally Displaced Persons: A Field Study of Internal Displacement and Available Protection in the Republic of South Sudan”, LUP Student Papers, 2012, p. 22, disponível em: http: / /lup.lub.lu.se/luur/download?func=downl oadFile\&recordOId $=3159781$ \&fileOId $=3224829$.

60 Ibidem, p. 20. 
Esta revista forma parte del acervo de la Biblioteca Jurídica Virtual del Instituto de Investigaciones Jurídicas de la UNAM

partir daí, um exame profundo da matéria por parte de inúmeras organizações internacionais.

Foi no âmbito da Organização das Nações Unidas, por intermédio de resolução emitida pela Comissão de Direitos Humanos ${ }^{61}$ (E/CN.4/ RES/1991/25), ${ }^{62}$ como apoio de países como Áustria e Noruega, ${ }^{63}$ que resoluções foram direcionadas à Assembleia Geral manifestando a urgência quanto a uma abordagem mais profunda e distinta sobre a questão do displacement e a proteção dos IDP's. Em um primeiro momento, o recém-nomeado Representante da Comissão sobre Internal Displacement, Francis Deng, fora encarregado da elaboração de um documento analítico sobre a situação jurídico-internacional dos IDP's, sobrevindo o Compilation and Analysis of Legal Norms ${ }^{64}$ ("Compilação e Análise de Normas Jurídicas"), onde se procedera à compilação de todos os instrumentos internacionais concernentes à matéria, tendo o mesmo sido apresentado à Assembleia Geral da ONU em 1996. ${ }^{65}$

Ressalte-se que, inobstante a lacuna de enquadramento e de efetividade normativa, há diversos instrumentos internacionais de Hard Law que tratam diretamente da matéria, ${ }^{66}$ mas tal não fora o suficiente para afastar a evidente desproteção das pessoas objeto de displacement, em especial devido a não aplicação dos mesmos por parte de diversos Estados, permanecendo aquelas sob contínua e flagrante situação de violação de direitos humanos. O referido Compilation and Analysis of Legal Norms veio traçar um panorama

61 Kälin, Walter, "How Hard is Soft Law? The Guiding Principles on Internal Displacement and the Need for a Normative Framework", Brooking Project, Washington D. C., diciembre de 2001, disponível em: https: / /www.brookings.edu/wp-content/uploads/2016/06/20011219.pdf.

62 UN Commission on Human Rights Internally Displaced Persons, 5/march/1991, disponível em: E/CN.4/RES/1991/25, https: / / www.refworld.org/docid/3b00fob1 c.html.

63 Cohen, Roberta, "Lessons Learned from the Development of the Guiding Principles on Internal Displacement”, Institute for the Study of International Migration, Washington D. C., octubre de 2013, disponível em: https://www.brookings.edu/research/lessons-learned-from-thedevelopment-of-the-guiding-principles-on-internal displacement/.

64 Internally Displaced Persons Compilation and Analysis of Legal Norms, Office of the United Nations High Commissioner for Human Rights, Geneva, United Nations High Commissioner for Human Rights, 1996, disponível em: https: / / digitallibrary.un.org/record / 228454.

65 Cohen, Roberta e Deng, Francis M., "The Genesis and the Challenges”, Forced Migration Review, Oxford, 2008, p. 4, disponível em: https://www.fmreview.org/sites/fmr/files/FMRdown loads / en / GuidingPrinciples10/cohen-deng.pdf.

66 Jörnrud, Martin, op. cit., p. 53. 
geral das possíveis legislações de direito internacional existentes e aplicáveis à problemática, concluindo pela necessidade de um tratamento mais específico. Inobstante a incidência múltipla de diversas disposições normativas sobre a questão, ${ }^{67}$ tais como as relativas ao direito internacional humanitário, direitos humanos, e direito dos refugiados, os IDP's permaneciam desprotegidos, nenhum dos referidos instrumentos foi capaz de captar e providenciar o suprimento das necessidades específicas das pessoas afetadas. ${ }^{68}$ Uma vez evidenciada a insuficiência jurídico-normativa a prevenir e proteger os IDP's, mais uma vez o Francis Deng fora encarregado de elaborar um documento que trouxesse à lume todo esse enquadramento normativo existente, intentando uma abordagem mais específica, mais clara e mais sistemática sobre as necessidades e deficiências, apresentando-o à Comissão de Direitos Humanos da ONU (E/CN.4/1998/53/Add.2) ${ }^{69}$ no ano de 1998, o então Guiding Principles on Internal Displacement. ${ }^{70}$

Questão relevante que se coloca está nas razões pelas quais, em que pesem a importância e urgência do tratamento da referida matéria, não se elaborara um tratado de Direito Internacional, mas sim apenas um documento com "princípios-guia” (Guiding Principles), supostamente de caráter não-vinculante, ${ }^{71}$ constituindo, portanto, mecanismo regulatório soft. ${ }^{72}$ Quatro são as razões para tanto, senão vejamos.

Em primeiro lugar, tendo em vista que os IDP's constituem objeto de fluxo migratório interno ao respectivo Estado de origem, de forte e prioritária incidência é a legislação (doméstica-interna) de cada Estado, tornando, portanto, a aplicação dos instrumentos de direito internacional, em especial os tratados sobre a matéria, de aplicação subsidiária. Ademais,

67 Lavoyer, Jean Philippe, "Comments on the Guiding Principles on Internal Displacement”, International Review of the Red Cross, Genebra, núm. 324, septiembre de 1998, disponível em: https://www.icrc.org/eng/resources/documents/article/other/57jpg9.htm.

68 Cohen, Roberta, “The Guiding...”, cit., pp. 463 e 464.

69 Guiding Principles on Internal Displacement, U.N. Doc. E/CN.4/1998/53/Add.2, United Nations General Assembly, 1998, disponível em: http://hrlibrary.umn.edu/instree/ GuidingPrinciplesonInternalDisplacement.htm.

70 Jörnrud, Martin, op. cit., p. 20.

71 Betts, Alexander, "Towards a «Soft Law» Framework for the Protection of Vulnerable Migrants”, New Issues in Refugee Research, Switzerland, núm. 162, agosto de 2008, p. 12. Neste sentido, Kälin, Walter, op. cit. Fala na natureza de "não-tratado" do instrumento.

72 Ratificando a natureza soft do Guiding Principles, cfr. Betts, Alexander, op. cit., p. 13. 
deve-se levar em consideração que muitos tratados não foram ratificados por diversos Estados, submetendo os IDP's à mercê da vontade estatal em razão do excesso burocrático dos respectivos processos legislativos de ratificação interna. ${ }^{73}$ Em segundo lugar, deixar que o tratamento se dê por instrumento dependente de ratificação por parte de cada Estado torna esta condicionada ao discricionário exercício da soberania estatal, em nada assegurando o necessário compliance por parte dos signatários. Como terceiro motivo, devido à "sensibilidade" da matéria, ${ }^{74}$ permanecem os Estados relutantes quanto à sua vinculação jurídica ao nível internacional, eis que em eventual descumprimento das respectivas disposições decorreriam sanções de ordem política. ${ }^{75}$ Por fim, a quarta razão, a clara inexistência de consenso político sobre a matéria, notadamente no que concerne a segura definição sobre internal displacement, a fixação dos termos iniciais e finais de proteção, regras sobre o fornecimento de recursos materiais, dentre outras questões, torna não recomendável a adoção de instrumentos estritamente vinculantes.

Dados os motivos alinhavados, optou-se, portanto, pela não adoção de um tratado ou outro instrumento de natureza hard, mas antes de um instrumento soft que, a despeito de não estritamente vinculante, pudesse promover o diálogo com a Hard Law, e assim contribuísse para o tratamento e desenvolvimento jurídico-político da problemática. Decerto que a adoção de Soft Law na matéria tem inúmeras vantagens, em especial a desnecessidade da submissão a um processo de aprovação demasiado burocrático e político, permitindo, assim, uma resposta mais eficiente e mais célere aos problemas dos "deslocamentos internos". ${ }^{76}$ Acresça-se também a ampliação da possibilidade de se alcançar um certo nível de consenso quando utilizados instrumentos de Soft Law, notadamente pela participação plural de múltiplos atores institucionais na feitura e elaboração dos documentos, recrudescendo tantos os inputs quanto os outputs de legitimidade. ${ }^{77}$

Por outro lado, como asseveram Roberta Cohen e Francis Deng, o processo de elaboração do Guiding Principles enfrentou alguns desafios,

73 Liao, Kuan-Wen, op. cit., p. 4.

74 Jörnrud, Martin, op. cit., pp. 20 e 21.

75 Betts, Alexander, op. cit., p. 13.

76 Cohen, Roberta, “The Guiding...”, cit., pp. 464-475.

77 Para uma visão geral de todas as vantagens quanto à adoção de Soft Law, cfr. Cohen, Roberta e Deng, Francis M., “The Genesis...”, cit., p. 4. 
dentre os quais se pode apontar: a oposição por parte de diversos governos sobre uma possível intervenção em seu espaço de soberania; as inúmeras divergências de conteúdo sobre a matéria, cabendo a tal processo soft buscar um mínimo de convergência de opiniões; e a necessidade de equilíbrio entre o exercício da soberania estatal e o cumprimento dos deveres de proteção solidária dos direitos humanos, assistindo aos IDP's nas diversas situações de violação de direitos. ${ }^{78}$ Nessa toada, um dos pontos centrais do Guiding Principles reside no conceito de "soberania como responsabilidade", através do qual se ressaltam dois elementos de indelével relevância: primeiro, a ideia de que o exercício da soberania estatal não traduz um fim em si mesmo, senão um fim e objetivos vinculados, sempre fundamentados e restringidos pelo valor da "dignidade da pessoa humana”, cabendo ao Estado exercê-la primordialmente em defesa dos direitos fundamentais e dos direitos humanos; e segundo, a responsabilidade (subsidiária) da comunidade internacional na proteção de tais direitos quando o Estado ultrapassa os devidos limites e exerce com inegável discricionariedade o seu poder soberano, violando direitos, seja comissiva ou omissivamente. ${ }^{79}$

Duas são as disposições constantes do Guiding Principles no mister, posto que refletem o consignado. A primeira, sob o princípio de no. 3, representa a deferência do espectro regulatório do documento e da comunidade internacional para com a atuação soberana (doméstica) de cada Estado, estatuindo ser das autoridade nacionais "o dever e a responsabilidade primária" (primary duty and responsibility) em prevenir, proteger e assistir todos aqueles afetados pelo displacement dentro de seu respectivo território. ${ }^{80} \mathrm{~A}$ segunda, constante do princípio de no. 25 , assentando o dever e a responsabilidade primárias das autoridades nacionais em fornecer a respectiva ajuda humanitária, dispõe que organizações internacionais, dentre outros atores, poderão fornecer os recursos que forem indispensáveis à proteção dos IDP's

78 Idem.

79 De acordo com Peters, Anne, "Humanity as the A and $\Omega$ of Sovereignty", The European Journal of International Law, Oxford, vol. 20, núm. 3, agosto de 2009, pp. 524-527. Exercer a "soberania como responsabilidade", obriga os Estados a dois deveres básicos: primeiro, a tomar como vetor do exercício protetivo os direitos fundamentais básicos; e segundo, que a proteção conferida vise a integridade da população do Estado e da comunidade internacional como um todo solidário.

80 Lavoyer, Jean Philippe, op. cit. 
sem que isso seja entendido como qualquer ameaça à soberania nacional, cabendo aos respectivos Estados receberem tais ações com boa-fé e sem qualquer ameaça de retaliação.

Nesse quadrante, um dos principais motivos para que o consenso sobre o tratamento internacional da matéria não fosse alcançado (o receio quanto a possíveis intervenções institucionais na esfera soberana dos Estados) viu-se contrabalanceado pela linha diretiva de deferência adotada pelo documento, priorizando-se a atuação interna dos Estados para a solução de problemas relacionados aos IDP's ("o dever e a responsabilidade primária”), algo que decerto, inobstante não ter gerado um posicionamento unânime dos Estados quanto à questão, ao menos reduziu a relutância dos mesmos, possibilitando o estabelecimento de um amplo diálogo institucional. A tal ladeia a irreprochável responsabilidade da comunidade internacional para com a proteção e assistência de todos aqueles afetados pelo fenômeno do displacement, reconhecendo-se a inviabilidade dos Estados se utilizarem do argumento do "exercício da soberania" para afastar qualquer ajuda humanitária ou barrarem a entrada de quaisquer recursos necessários e indispensáveis à assistência dos IDP's.

Desta feita, reafirmando o valor da utilização da Soft Law na problemática, o fato de se ter operado um enquadramento jurídico-internacional mais protetivo e percuciente na matéria por via de um instrumento a priori não-vinculante, tal qual o Guiding Principles, tornou os Estados mais dispostos ao diálogo e propensos ao consenso regulatório, uma vez que o peso do non-compliance aqui não é o mesmo existente no âmbito de um tratado internacional, em que pesem haver ônus outros, como restrições, embargos e censuras de ordem político-institucional. ${ }^{81}$ Por outro lado, ainda que tal intento fosse objeto de instrumentos hard, cediço é que dentro do espectro de globalização há muito que o exercício da soberania estatal não se dá nos moldes positivistas, vendo-se deveras temperado, pois de "bem comum" centralizado na figura do Estado transmudou-se à proteção e à realização de "bem comum" de ordem cosmopolita , ${ }^{82}$ mediante fenômenos como o da internacionalização e o da constitucionalização internacional que tornaram

81 Ver, por todos, Cohen, Roberta e Deng, Francis M., “The Genesis...”, cit., p. 4.

82 Petersmann, Ernst-Ulrich, "How to Constitutionalize International Law and Foreign Policy for the Benefit of Civil Society?", Michigan Journal of International Law, Michigan, vol. 20, núm. 1, 1998, pp. 7-9. 
a ideia de "soberania" vinculada ao valor da "dignidade humana", ${ }^{83}$ numa forma condicionada de exercício. ${ }^{84}$

Procedendo a uma análise jurídico-estrutural do Guiding Principles, vejamos alguns pontos de relevo no que tange à sua estrutura, fundamentos, legitimidade e consequências de adoção, em consonância com toda base argumentativa expendida ao longo do presente excurso. Estruturalmente, traduz instrumento soft, cuja não-vinculatividade constitui característica essencial apontada pela doutrina,${ }^{85}$ posto que aprovado por procedimentos outros que não aqueles utilizados pelas fontes normativas tradicionais do Direito Internacional clássico. ${ }^{86}$ Entretanto, o fato de constituir instrumento soft, baseado em uma "não-vinculatividade formal", não significa que seja o mesmo desprovido de qualquer normatividade, eis que instrumental de quilate jurídico incontestável.

Analisando-se a estrutura das disposições contidas no Guiding Principles, a ausência de elementos coercitivos diretos (sanções) aponta, ao menos a princípio, para a rejeição do status de genuínas normas jurídicas. Conquanto, uma leitura mais cautelosa de sua estrutura e conteúdo possibilita perceber a presença de elementos normativos, como a existência de pressupostos de fato, o estabelecimento e a configuração de âmbitos de proteção de direitos, vedações a determinados comportamentos e situações, utilizando-se, em determinados casos, a linguagem prescritiva (semiótica jurídica) das normas jurídicas - linguagem esta da natureza de "dever-ser". ${ }^{87}$

A título de exemplo, vejamos: o princípio 6, no. 1 e 2, reconhece um direito (não ser arbitrariamente submetido à evasão de seu local ou região de moradia) cujo âmbito de proteção alberga um dever (dever de proteção e prevenção à evasão arbitrária) e uma proibição (não operar a

83 Otero, Paulo, Instituições políticas e constitucionais, 2a. reimp., Coimbra, Almedina, 2016, vol. 1, p. 569.

84 Mooney, Erin, "The Guiding Principles and the Responsibility to Protect”, Forced Migration Review, Oxford, diciembre de 2008, p. 12.

85 Betts, Alexander, op. cit., p. 12.

86 Cohen, Roberta, “The Guiding...”, cit., p. 459.

87 Neste sentido, Glos, George E., "The Normative Theory of Law”, William \& Mary Law Review, Virginia, vol. 11, núm. 1, art. 6, 1969, pp. 159 e 160. Ressalta que uma "norma” é composta por três elementos básicos, quais sejam: primeiro, que algo (conteúdo) "deve ser"; segundo, há a estatuição de uma obrigação ou dever; e terceiro, que os elementos anteriores são conectados por uma relação de imputabilidade. 
evasão arbitrária) direcionada às autoridades nacionais e internacionais; o princípio 10 , no. 1 , reconhece o "direito à vida inerente a todo ser humano", cuja proteção é veiculada por meio de linguagem prescritiva, além de estipular os pressupostos de fato sob os quais tal proteção deve ocorrer (“devem ser protegidos particularmente contra”); e o princípio 18, no. 2, determina um standard mínimo de proteção, cuja essência não deve restar violada, prescrevendo deveres a serem respeitados pelas autoridades nacionais e internacionais.

Dos exemplos anteriores, verifica-se que as estruturas semiótica e semântica das disposições atestam o seu arquétipo normativo, as quais Karl Larenz afirma constituírem a "forma linguística" da "regra do Direito", 88 cuja normatividade não se pode refutar. Para tanto, duas são as razões: primeira, possuem clara pretensão de validade, ${ }^{89}$ eis que se pautam em uma autodeterminação heterovinculativa, ou seja, sustentam per se uma força geral de aplicação quando preenchidos seus respectivos pressupostos de fato; e segunda, sobrevém um consequente (relação normativa de imputabilidade $)^{90}$ quando do preenchimento de sua estatuição de fato, qual seja, uma vedação ou uma obrigação, um facere ou um non facere.

Ainda em termos estruturais, muitas de suas disposições possuem cariz principiológico, cujos elementos linguísticos dotados de generalidade e abstração, expressos em cláusulas gerais, abertas e dúcteis, acabam por fornecer uma carga política, ideológica e axiológica ao documento, ponto este a partir do qual muitos defendem a ausência de normatividade e sua característica de instrumento meramente político. ${ }^{91}$ Como exemplo, o princípio 23, no. 1, através do qual resta garantido o direito universal à educação, cuja disposição, apesar de conter todos os elementos normativos já abordados, possui conteúdo de carga política irrefutável, carecendo de elementos outros - tais como fatores socio-econômicos, políticos, ideológicos - para que seja contextualizadamente apreendido. Conquanto, a indigitada estrutura principiológica não configura razão suficiente para que se lhes negue normatividade ou qualquer qualida-

88 Larenz, Karl, Metodologia da ciência do direito, 4a. ed., trad. de José Lamego, Lisboa, Fundação Calouste Gulbenkian, 2005, pp. 349-353.

89 Ibidem, p. 349.

90 Glos, George E., op. cit., p. 160.

91 Hillgenberg, Hartmut, op. cit., p. 499. 
de jurídico-normativa, eis que, ainda nas situações em que o material normativo constante da disposição necessite de densificação, tal qual os possíveis conceitos de "educação" no âmbito do supracitado princípio 23, no. 1 , o texto normativo não se confunde com a norma decorrente de seu processo de compreensão, interpretação e aplicação. Destarte, do princípio 20, que garante a todos aqueles afetados pelo fenômeno do displacement o direito a ser reconhecido como pessoa perante a lei, a despeito de sua estrutura aberta, as seguintes normas podem ser dele deduzidas: "a todos é reconhecido o tratamento perante a lei e o Direito"; "a todos cabe igual tratamento perante a lei"; "a todos cabe a proteção da lei e do Direito"; "é vedado o tratamento discriminatório"; “é proibido a qualquer autoridade desconsiderar assistência e proteção da lei aos afetados pelo displacement".

O fato de o Guiding Principles constituir instrumento soft, ao invés de retirar-lhe aprioristicamente o caráter normativo, ${ }^{92}$ acaba por afirmar ainda mais o seu valor jurídico-normativo, posto que, dado o contexto de sua gênese, não veio criar ou estruturar um enquadramento jurídico do fenômeno do internal displacement, mas sim reconfigurar e/ou remodelar o tratamento (insuficientemente) endereçado por instrumentos de Hard Law na matéria, mas que se quedavam repletos de regulações esparsas e insuficientes. ${ }^{93}$ Assim, as disposições constantes do Guiding Principles possuem uma normatividade reforçada, uma vez que igualmente se assentam em inegáveis normas jurídicas de Direito Internacional Público (notadamente tratados internacionais), trazendo apenas uma abordagem mais sistemática e direcionada às necessidades dos IDP's, ${ }^{94}$ operando como elemento interpretativo às diversas autoridades e instituições envolvidas com a proteção e assistência aos afetados pelo internal displacement. Ao contrário de outros documentos soft, cujas disposições de certa forma inovam no tratamento jurídico de determinada matéria, o Guiding Principles traz uma abordagem focada e direcionada às necessidades específicas dos IDP's, abordagem esta que Roberta Cohen defende ser desenvolvida

92 Cárdenas Castañeda, Fabián Augusto, op. cit., p. 389.

93 Sobre tal insuficiência, Cohen, Roberta, “The Guiding...”, cit., pp. 463 e 464. Ainda, cfr. Jörnrud, Martin, op. cit., p. 49.

94 Sobre a necessidade de uma proteção mais específica e direcionada aos IDP's, cfr. Lavoyer, Jean Philippe, op. cit. 
a partir de uma dupla perspectiva, a dos direitos (rights-based approach) e a das necessidades (needs-based approach), ${ }^{95}$ intentando, como objetivo principal, o reforço de disposições hard já existentes.

No que tange à sua legitimidade, deve a análise levar em consideração duas perspectivas básicas, quais sejam, a formal (procedimento e processo de elaboração e aprovação) e a material (conteúdo, interações e dinâmicas existentes). Em primeiro lugar, no tocante à legitimidade formal, algumas vozes têm direcionado suas manifestações no sentido de negar-lhe qualquer substrato jurídico, aduzindo o fato de que o mesmo não surgira pelos procedimentos de elaboração e aprovação de tratados internacionais (aprovação de Hard Law), ${ }^{96}$ constituindo, assim, apenas um documento soft dotado de meras preferências políticas ou recomendações. A tal, acresça-se a questão relacionada à imbricação de diversos atores não-estatais na sua configuração, o que em tese lhe retiraria qualquer elemento de legitimidade, principalmente no que tange ao cariz democrático. ${ }^{97}$

Entretanto, na contramão das opiniões críticas, o fato de constituir Soft Law, em especial no tocante à participação de diversos atores (estatais e não-estatais, públicos e privados) em seu processo de elaboração, reforça sua legitimidade, ao que se pode veicular duas razões fundamentais: primeira, procede-se, assim, a uma compensação do déficit de legitimidade próprio ao Direito Internacional, ${ }^{98}$ eis que a pluralidade participativa ${ }^{99}$ realimenta os grandes centros de decisão-regulação com eflúvios de democraticidade, recrudescendo seus respectivos inputs e outputs de fundamentação e justificação; e segunda, porque a imbricação de uma diversidade de atores torna a elaboração do documento um processo de criação multidimensional, compreendendo uma pluralidade de perspectivas sobre a matéria objeto

95 Cohen, Roberta, “The Guiding...”, cit., p. 463.

96 Por tal motivo, alguns Estados encontravam-se relutantes em reconhecer-lhe qualquer significância jurídica. Para tanto, cfr. Cohen, Roberta e Deng, Francis M., "The Genesis...", cit., p. 4.

97 Defendendo a mera virtualidade da pluralidade participativa nos processos de elaboração e adoção de instrumentos de caráter soft, cfr. Di Robilant, op. cit., p. 506.

98 Terpan, Fabien, "Soft Law in the European Union: The Changing Nature of EU Law", European Law Journal, New Jersey, noviembre de 2013, disponível em: https://hal.archivesouvertes.fr/halshs-00911460/document.

99 Barelli, M., "The Role of Soft Law in the International Legal System: The Case of the United Nations Declaration on the Rights of Indigenous People”, International and Comparative Law Quarterly, Cambridge, vol. 58, octubre de 2009, p. 965. 
de tratamento, evitando uma abordagem centralizada e estática a fim de se atingir um consenso ideal mínimo.

No que concerne à análise acerca da legitimidade material do Guiding Principles como instrumento soft, faz-se necessário o recurso discursivo aos referidos conceitos de Governança Global e de Transconstitucionalismo, nos termos dos argumentos já alinhavados. Em sede de Governança Global, instrumentos de Soft Law, a exemplo do Guiding Principles, possuem duas funções básicas: primeiro, intentar a convergência de opiniões em vista do consenso acerca de determinada matéria, conferindo, em tempo hábil, uma responsividade mínima às questões apresentadas à regulação; e segundo, engendrar standards jurídico-políticos mínimos para atuação de diversos atores na problemática, sejam públicos ou privados, governamentais ou não-governamentais, constituindo uma genuína forma de “pressão", como defende Dinha L. Shelton, ${ }^{100}$ para que os Estados (dentre outros envolvidos) se amoldem às expectativas no instrumento. Ademais, ao Guiding Principles deve ser reconhecida uma "força constitucional" na esteira das "Constituições Civis" defendidas por Günther Teubner, eis que emerge como documento-standard direcionado à regulação de um subsistema social (os “deslocados internos"), cujo conteúdo perfaz-se deveras integrado por elementos de inegável cariz constitucional, notadamente no que se refere à proteção de direitos fundamentais (e humanos), podendo assim considera-lo a verdadeira "Constituição dos Internal Displaced Persons”. Desta feita, a sua legitimidade material provém não apenas da sua natureza, operacionalizado como um instrumental de Governança Global, mas igualmente pela matéria que veicula, elementos de irrefutável nível jurídico-constitucional.

Ainda, não se deve olvidar que, igualmente no tocante à Governança Global, a necessidade e a urgência quanto ao tratamento unificado e efetivo à problemática do internal displacement como subsistema parcial desprovido de regulação eficaz, acaba por legitimar um movimento de autorregulação onde a imbricação plural de atores / colaboradores, atuando com a força "do público" em paralelo aos fóruns estatais de regulação, reitera a legitimidade do instrumento. Nessa toada, o surgimento de um

100 Shelton, Dinah L., "Soft Law", GW Law Faculty Publications \& OtherWorks, Washington D. C, 2008, p. 14, disponível em: https://scholarship.law.gwu.edu/cgi / viewcontent.cgi?article=204 8 \&context $=$ faculty_publications. 
instrumento soft tal qual o Guiding Principles, através do qual o subsistema social dos "deslocados internos" passa a possuir um vetor normativo mínimo de direcionamento, funcionalizado a prestar o auxílio e o reforço necessários aos instrumentos de Hard Law existentes na matéria, torna irreprochável a sua legitimidade material.

Por fim, insta a análise de sua legitimidade pelos termos do Transconstitucionalismo. De início, deve-se partir daquilo que Ernst-Ulrich Petersmann afirma ser o processo de concessão de funções constitucionais ao Direito Internacional e a atores internacionais outros, ressaltando a indispensável interconexão comunitária decorrente do processo de globalização. ${ }^{101}$ Para a análise da legitimidade do Guiding Principles sob essa perspectiva, faz-se necessária a operacionalização dos referidos topoi "interculturalidade", "intersemioticidade" e "interconstitucionalidade".

A questão da interculturalidade pode ser observada por três vias: a primeira, as disposições constantes do instrumento prezam por soluções transconstitucionais que partem de perspectivas culturais heterogêneas, levando em consideração na resolução dos respectivos problemas as informações culturais de cada esfera social afetada pelo internal displacement; ${ }^{102}$ segunda, pela aplicação e interpretação das respectivas, seja por atores públicos ou privados, governamentais ou não-governamentais, há sempre a troca de informações e de elementos sócio-culturais, pois, como mecanismos de "pressão" à conformação das expectativas comportamentais por parte dos Estados e organizações internacionais, os diálogos políticos, diplomáticos, e científico-acadêmicos acabam por traçar uma dinâmica comparada entre as diversas perspectivas de aplicação, influenciando a análise recíproca entre os Estados; e a terceira, o discurso constitucional de legitimação pelos direitos fundamentais (e humanos), constante do texto do Guiding Principles, intenta o equilíbrio entre uma visão homogênea do conceito de direitos humanos e uma visão heterogênea desses direitos, cujas informações culturais constituem os topoi para a aplicação mais realística e concreta (needs-based approach) das respectivas disposições.

101 Petersmann, Ernst-Ulrich, op. cit., p. 28.

102 Sobre a integração cultural no contexto de uma "comunidade inclusiva" intermediada e possibilitada pelos diálogos constitucionais, cfr. Canotilho, J. J. Gomes, "Brancosos”..., cit., pp. 271 e ss. 
Sob a ótica da intersemioticidade, ${ }^{103}$ duas são as perspectivas de legitimação: primeiro, as disposições constantes do Guiding Principles possuem uma estrutura linguística e semântica similar às disposições normativas de instrumentos hard, notadamente ao reconhecer/estipular direitos, correlacionando-os a um dever comissivo ou omissivo, e contextualizando-os junto a determinadas circunstâncias de fato; e segundo, a linguagem do discurso constitucional de proteção aos direitos fundamentais (e humanos) é produto do constante intercâmbio para com o material normativo dos instrumentos de Hard Law, demonstrando a inter-relação semiótica existente entre ambas as categorias, deixando o respectivo conteúdo sempre aberto ao fluxo de otimização.

No tocante à interconstitucionalidade, justifica-se a sua legitimidade por três perspectivas: primeira, a linguagem jurídico-constitucional que permeia todo o documento, em especial quanto à proteção dos direitos fundamentais (e humanos) dos IDP's; segunda, a sua integração e diálogo semânticos com outros documentos constitucionais pelo discurso da proteção e inclusão das minorias sociais afetadas; e terceira, no âmbito da praxis constitucional, a integração de suas disposições como recurso discursivo no âmbito do controle de constitucionalidade de diversos Estados, tal como reconhecera a Corte Constitucional Colombiana ${ }^{104}$ (p. ex., Auto no. 251/08, 2a. Sala de Revisão) ao compreender as disposições do Guiding Principles como integrante do bloco de constitucionalidade para fins de judicial review e para a fundamentação de suas próprias decisões. ${ }^{105}$

Pela conjugação dos topoi "interculturalidade", "intersemioticidade" e "interconstitucionalidade”, o processo de transconstitucionalidade encetado pela interpretação e aplicação multidimensional do Guiding Principles, notadamente pelas normas extraíveis de sua semiótica jurídico-constitucional, atesta a sua legitimidade material (discurso jurídico-constitucional) e formal (dinâmica de formação e aplicação). Em verdade, o que se defende é que, como cerne

103 Quanto à intersemioticidade, Canotilho, J. J. Gomes, “Brancosos”..., cit., p. 279. Afirma: "...intersemioticidade implica articulação da busca de regras referentes à produção e interpretação dos textos constitucionais com a formulação de discursos e práticas sociais num contexto cultural pluralista”.

104 Auto no. 251 / 08, 2a. Sala de Revisão, Corte Constitucional de la República de Colombia, 2008, disponível em: https: / / www.corteconstitucional.gov.co/Relatoria / autos/2008/A251-08.htm.

105 Diagne, Khassim e Entwisle, Hannah, "UNHCR and the Guiding Principles", Forced Migration Review, Oxford, 2008, p. 34. 
regulatório das questões relacionadas aos IDP's, o Guiding Principles constitui a "Constituição Global”"106 dos "deslocados internos", interagindo com diversas Constituições e outros documentos de Direito Internacional.

Desta feita, torna-se incabível refutar a qualidade de fonte normativa dos instrumentos de Soft Law, notadamente sob o exemplo do Guiding Principles. As relações existentes entre Hard e Soft Law ultrapassam o simples paralelismo e a mera separação dicotômica "vinculante e não-vinculante", ${ }^{107}$ antes alçando ares de complementação e interação. ${ }^{108}$ Sob o exemplo do Guiding Principles, observa-se a capacidade dos instrumentos soft em gerar standards normativos, expectativas comportamentais e vetores interpretativos para a aplicação de tratados e convenções internacionais (influenciando diretamente instrumentos de Hard Law), o potencial em cumprir a tarefa de incorporação, produção e implementação normativa interna de cada Estado (através de sua legislação doméstica), bem como a sua propensão à formação da opinio iuris, contribuindo até mesmo para a formação de common law em Direito Internacional. Portanto, reconhecida a sua normatividade e legitimidade, o Guiding Principles atua como inegável instrumento normativo, ao que deve ser reconhecido como genuína fonte de Direito Internacional e instrumental efetivo no tratamento (prevenção e repressão) da problemática relativa ao internal displacement. Outrossim, para além da problemática relativa ao internal displacement, deve-se reconhecer a Soft Law como categoria doutrinária que, a despeito de albergar instrumentos de diferenciada estrutura, confere uma nova dinâmica às fontes do Direito Internacional num contexto de Governança Global.

\section{CONCLUSÃO}

Partindo da suposta ausência de normatividade dos instrumentos soft, intentou-se, ao longo do presente excurso, a defesa da legitimidade da Soft

$106 \mathrm{Na}$ defesa de uma "Constituição Global” a partir dos direitos fundamentais, $c f r$. Canotilho, J. J. Gomes, “Brancosos”..., cit., p. 289.

107 Schaffer, Gregory C. e Pollack, Mark A., "Hard Law v. Soft Law: Alternatives, Complements, and Antagonists in International Governance”, Minnesota Law Review, Minnesota, vol. 94, núm. 3, 2010, pp. 712 e 713.

108 Terpan, Fabien, op. cit. 
Law como fonte normativa do Direito Internacional no contexto funcional da Governança Global. Através da análise do Guiding Principles on Internal Displacement como instrumento soft voltado ao tratamento jurídico-político dos "deslocados internos", buscou-se ressaltar, notadamente pelas suas disposições, que a sua legitimidade como fonte normativa pode ser (re)construída com base na dinâmica material e procedimental sob a qual emergiu e na qual se vê operacionalizada. A argumentação intentada centrou-se em sua plural legitimação, que se dá tanto pela matéria como pela forma. Para tanto, lançou-se mão dos conceitos de Governança Global e Transconstitucionalismo como recursos discursivos, oferecendo-se como argumentos de fecho os seguintes.

1) Tanto o Direito Constitucional como o Direito Internacional não mais podem ser compreendidos na esteira de uma perspectiva fechada e restrita ao elemento da "estatalidade". O processo de globalização provocou (e tem provocado) a inegável mutação no aspecto regulatório-decisório do cenário mundial, cujos novos desafios, dada a afetação direta a temas transversais à comunidade global, têm cada vez mais exigido uma responsividade no contexto da Governança Global.

2) Em razão da emergência de novas problemáticas a serem tratadas no contexto dessa (nova) Governança Global, os instrumentos normativos utilizados como fontes clássicas do Direito Internacional, a exemplo do art. 38 do Estatuto da Corte Internacional de Justiça, não mais têm sido suficientes ao endereçamento jurídico-político daquelas, razão pela qual se tem observado uma ampliação no complexo de instrumentais normativos com vistas a conferir uma responsividade internacional mais célere e eficaz.

3) O conceito de Soft Law vem justamente ao encontro da satisfação de tal necessidade. Com vistas a evitar o engessamento do tratamento jurídico-político de temas estruturais à comunidade global no âmbito dos processos políticos de regulação-decisão internacional e igualmente no contexto dos processos legislativos internos de cada Estado, o manejo de instrumentais outros como recomendações, acordos, linhas-guia, dentre outros expedientes soft, tem recrudescido.

4) A despeito de sua alegada característica política e de não-vinculatividade, observa-se que, mesmo paulatinamente, os instrumentos soft têm sido cada vez mais manejados como expedientes eficientes no 
tratamento de temáticas afetas às sociedades como um todo, num contexto de administração regulatória e decisória multinível, razão pela qual se pode afirmar que constituem aparatos normativos de Governança Global. A isso, some-se a pluridimensional participação no processo de elaboração de tais instrumentos e o recurso ao discurso jurídico-constitucional, conferindo-lhes evidente legitimidade formal-subjetiva e material.

5) No que tange à defesa da normatividade dos instrumentos soft, notadamente sob o exemplo do Guiding Principles on Internal Displacement, observou-se que suas disposições possuem elementos normativos em sua estrutura, quais sejam, a estatuição de um conteúdo jurídico (um direito, por exemplo), a vinculação de uma obrigação ou dever, e a existência de uma relação de imputação entre ambos.

6) Para a análise da sua legitimidade, foram manejados os topoi "interculturalidade", "intersemioticidade" e "interconstitucionalidade", cuja operação integrada funcionaliza o processo de transconstitucionalidade (Transconstitucionalismo), justificando-se a sua juridicidade pelo discurso material que lhe é subjacente. A isso, acrescente-se a sua compreensão, como já referido, no contexto de um processo multinível de Governança Global.

7) À guisa de conclusão, deve-se afastar a suposta caracterização de "não-direito" da Soft Law. Sob o exemplo do Guiding Principles on Internal Displacement, afirma-se a sua plena juridicidade e normatividade, legitimando-a pela dinamicidade a que se vê vinculada, integrando-a claramente ao sistema jurídico internacional, ladeando fontes como tratados, convenções, costumes, pactos e decisões de Tribunais e Cortes Internacionais, constituindo, assim, "Direito" propriamente considerado.

\section{BIBLIOGRAFIA}

BALKIN, J. M., "The Hohfeldian Approach to Law and Semiotics", University of Miami Law Review, Florida, vol. 44, núm. 5, 1990.

BARELLI, M., "The Role of Soft Law in the International Legal System: The Case of the United Nations Declaration on the Rights of Indigenous Peo- 
ple”, International and Comparative Law Quarterly, Cambridge, vol. 58, octubre de 2009.

BARroso, Luís Roberto, "Here, There, and Everywhere: Human Dignity in Contemporary Law and in the Transnational Discourse", Boston College International \& Comparative Law Review, Massachusetts, vol. 35, núm. 2, art. 2, 2012.

BETTS, Alexander, "Towards a «Soft Law» Framework for the Protection of Vulnerable Migrants", New Issues in Refugee Research, Switzerland, núm. 162, agosto de 2008.

Berman, Paul Schiff, "From International Law to Law and Globalization", Columbia Journal of Transnational Law, Nueva York, vol. 43, núm. 2, 2005.

Blahoz, Joseph, "The Theory of Global Governance, Constitutionalization and Comparative Constitutional Law", The Lawyer Quarterly: International Journal for Legal Research, Praga, vol. 43, núm. 3, 2013.

BogDANDY, Armin von, "Demokratie, Globalisierung, Zukunft des Völkerrechts. Eine Bestandaufnahme”, Zeitschrift für Ausländisches Öffentliches Recht undVölkerrecht, Heidelberg, vol. 63, 2003.

Canotilho, J. J. Gomes, "Brancosos" e interconstitucionalidade: itinerários dos discursos sobre a historicidade constitucional, 2a. ed., Coimbra, Almedina, 2008.

Canotilho, J. J. Gomes, Direito constitucional e teoria da Constituição, 7a. ed., Coimbra, Almedina, 2003.

CÁrdenas Castañeda, Fabián Augusto, "A Call for Rethinking the Sources of International Law: Soft Law and the other Side of the Coin", Anuario Mexicano de Derecho Internacional, México, vol. XIII, 2013.

CASS, Deborah Z., "The Constitutionalization of International Trade Law: Judicial Norm-Generation as the Engine of Constitutional Development in International Trade", European Journal of International Law, Oxford, vol. 12, núm. 1, 2001.

CoHEn, Roberta, "Lessons Learned from the Development of the Guiding Principles on Internal Displacement", Institute for the Study of International Migration, Washington D. C., octubre de 2013, disponível em: https: / / www.brookings.edu/research /lessons-learned-from-the-development-of-the-guiding-principles-on-internal displacement/.

CoHen, Roberta, "The Guiding Principles on Internal Displacement: An Innovation in International Standard Setting”, Global Governance, Utah, núm. 10, 2004. 
Esta revista forma parte del acervo de la Biblioteca Jurídica Virtual del Instituto de Investigaciones Jurídicas de la UNAM

Cohen, Roberta e Deng, Francis M., "The Genesis and the Challenges", Forced Migration Review, Oxford, 2008, p. 4, disponível em: https: / /www. fmreview.org/sites/fmr/files/FMRdownloads/en/GuidingPrinciples10/cohen -deng.pdf.

Convention and Protocol Relating to the Status of Refugees, Resolution 2198 (XXI), United Nations General Assembly, disponível em: https: / / www.unhcr.org/3b66c2aa10.

Diagne, Khassim e ENTWISLE, Hannah, "UNHCR and the Guiding Principles", Forced Migration Review, Oxford, 2008.

Di Robilant, Anna, "Genealogies of Soft Law", The American Journal of Comparative Law, Oxford, vol. 54, núm. 3, julio de 2006.

DunOFF, Jeffrey L., "Constitutional Conceits: The WTO's «Constitution» and the Discipline of International Law", European Journal of International Law, Oxford, vol. 17, núm. 3, 2006.

Ferris, Elizabeth e Bergmann, Jonnas, "Soft Law, Migration and Climate Change Governance", Journal of Human Rights and Environment, Cheltenham, vol. 8, núm. 1, marzo de 2017.

GARCIA, Frank J., "Introduction: Globalization, Power, States, and the Role of Law", Boston College Law Review, Massachusetts, vol. 54, núm. 3, art. 3, 2013.

GLOS, George E., “The Normative Theory of Law”, William \& Mary Law Review, Virginia, vol. 11, núm. 1, art. 6, 1969.

Granoff, Jonathan, "Pacta Sunt Servanda: Nuclear Weapons and Global Secure Sustainable Development", Southwestern Journal of International Law, California, vol. 21, núm. 2, marzo-mayo de 2015.

Guiding Principles on Internal Displacement, U.N. Doc. E/ CN.4/1998/53/Add.2, United Nations General Assembly, 1998, disponível em: http: / / hrlibrary.umn.edu/instree/GuidingPrinciplesonInternalDisplacement.htm.

HASANAJ, Shkelzen, "Multiculturalism vs. Interculturalism: New Paradigm? (Sociologic and Juridical Aspects of the Debate between the two Paradigms)?”, Journal of Education \& Social Policy, Nueva York, vol. 4, núm. 2, junio de 2017.

HESSE, Konrad, Grundzüge desVerfassungsgrechts der Bundesrepublik Deutschland, 20a. ed., Heidelberg, C. F. Müller Verlag, 1999.

Hillgenberg, Hartmut, “A Fresh Look at Soft Law”, European Journal of International Law, Oxford, vol. 10, núm. 3, 1999. 
HIRSCH, Moshe, "The Freedom of Proselytism under the Fundamental Agreement and International Law", Catholic University Law Review, Washington, vol. 47, núm. 2, art. 6, diciembre-febrero de 1998.

InTERnally Displaced PeRsons COMPILATION AND ANAlysis OF LEGAL Norms, Office of the United Nations High Commissioner for Human Rights, Geneva, United Nations High Commissioner for Human Rights, 1996, disponível em: https: / / digitallibrary.un.org/record/228454.

JÖRnRUD, Martin, "International Protection of Internally Displaced Persons: A Field Study of Internal Displacement and Available Protection in the Republic of South Sudan”, LUP Student Papers, 2012, p. 22, disponível em: http://lup.lub.lu.se/luur/download?func=downloadFile\&recordOI $d=3159781$ \&fileOId $=3224829$.

KÄLIN, Walter, "How Hard is Soft Law? The Guiding Principles on Internal Displacement and the Need for a Normative Framework", Brooking Project, Washington D. C., diciembre de 2001, disponível em: https: / /www. brookings.edu/wp-content/uploads/2016/06/20011219.pdf.

KenNEDY, David, “The Sources of International Law", American University International Law Review, Washington, vol. 2, núm. 1, art. 1, 1987.

KennetT, Steven A., "Hard Law, Soft Law and Diplomacy: The Emerging Paradigm for Intergovernmental Cooperation in Environmental Assessment”, Alberta Law Review, Alberta, vol. 31, núm. 4.

KRISCH, Nico, "Global Governance as Public Authority: an Introduction", International Journal of Constitutional Law, Oxford, vol. 10, núm. 4, octubre de 2012.

LARENZ, Karl, Metodologia da ciência do direito, 4a. ed., trad. de José Lamego, Lisboa, Fundação Calouste Gulbenkian, 2005.

LiAO, Kuan-Wen, "International Protection for Internally Displaced Persons", All Theses and Dissertations, Washington University Open Scholarship, enero de 2009, pp. 1-85, disponível em: https://openscholarship. wustl.edu/cgi / viewcontent.cgi?article $=1471$ \&context $=$ etd.

Lavoyer, Jean Philippe, "Comments on the Guiding Principles on Internal Displacement”, International Review of the Red Cross, Genebra, núm. 324, septiembre de 1998, disponível em: https://www.icrc.org/eng/resources/ documents/article/other/57jpg9.htm.

Lichtenstein, Cynthia C., "Hard Law v. Soft Law: Unnecessary Dichotomy?", The International Lawyer, Chicago, vol. 35, núm. 4, diciembre-febrero de 2001. 
MAYER, Ann Elizabeth, "Universal versus Islamic Human Rights: A Clash of Cultures or a Clash with a Construct?”, Michigan Journal of International Law, Michigan, vol. 15, núm. 2, 1994.

MCCRUDDEN, Christopher, "Human Dignity and Judicial Interpretation of Human Rights", The European Journal of International Law, Oxford, vol 19, núm. 4, 2008.

MoOney, Erin, "The Concept of Internal Displacement and the Case for Internally Displaced Persons as a Category of Concern”, Refugee Survey Quarterly, Oxford, vol. 24, núm. 3, septiembre de 2005.

MoOney, Erin, "The Guiding Principles and the Responsibility to Protect", Forced Migration Review, Oxford, diciembre de 2008.

NEves, Marcelo, "Do diálogo entre as cortes supremas e a Corte Interamericana de Direitos Humanos ao transconstitucionalismo na América Latina”, Revista de Informação Legislativa, Brasília, año 51, núm. 201, 2014.

Neves, Marcelo, Transconstitucionalismo, São Paulo, Editora WMF Martins Fontes, 2009.

OLIVIER, Michèle, “The relevance of «soft law» as source of international human rights", The Comparative and International Law Journal of Southern Africa, Southern Africa, vol. 35, núm. 3, 2002.

OTERO, Paulo, Instituições políticas e constitucionais, 2a. reimp., Coimbra, Almedina, 2016, vol. 1.

PETERS, Anne, "Humanity as the A and $\Omega$ of Sovereignty", The European Journal of International Law, Oxford, vol. 20, núm. 3, agosto de 2009.

PETERS, Anne, “The Merits of Global Constitutionalism”, Indiana Journal of Global Legal Studies, Indiana, vol. 16, núm. 2, junio-agosto de 2009.

Petersmann, Ernst-Ulrich, "How to Constitutionalize International Law and Foreign Policy for the Benefit of Civil Society?", Michigan Journal of International Law, Michigan, vol. 20, núm. 1, 1998.

RochA, Leonel Severo e TONET, Fernando, “A interconstitucionalidade como produção jurídica descentralizada dentro de novas observações estatais", Revista Brasileira de Estudos Políticos, Belo Horizonte, núm. 115, julio-diciembre de 2017.

SCHAFFER, Gregory C. e POllack, Mark A., "Hard Law v. Soft Law: Alternatives, Complements, and Antagonists in International Governance", Minnesota Law Review, Minnesota, vol. 94, núm. 3, 2010. 
SCHAFFER, Gregory C. e POLlaCK, Mark A., "Hard versus Soft Law in International Law Security”, Boston College Law Review, Massachusetts, vol. 52, núm. 4, art. 1, 2011.

Shelton, Dinah L., "Soft Law", GW Law Faculty Publications \& Other Works, Washington D. C, 2008, p. 14, disponível em: https: / /scholarship.law.gwu. edu/cgi / viewcontent.cgi?article $=2048$ \&context =faculty_publications .

SOUSA SANTOS, Boaventura de, "Toward a Multicultural Conception of Human Rights", en Hernández-Truyol, Berta (ed.), Moral Imperialism. A Critical Anthology, New York University Press, 2002.

TERPAN, Fabien, "Soft Law in the European Union: The Changing Nature of EU Law", European Law Journal, New Jersey, noviembre de 2013, disponível em: https: / / hal.archives-ouvertes.fr / halshs-00911460/document.

Teubner, Günther, "Global Private Regimes: Neo-Spontaneous Law and Dual Constitution of Autonomous Sectors inWorld Society?", en LADEUR, Karl-Heinz (ed.), Globalization and Public Governance, Aldershot, Ashgate Publishing, 2004.

TEUBNER, Günther, "Globale Zivilverfassungen: Alternativen zur staatszentrierten Verfassungstheorie", Zeitschrift für Ausländisches Öffentliches Recht undVölkerrecht, Heidelberg, núm. 63, 2003.

Un COMmission on Human Rights Internally DisPlaced Persons, 5/march/1991, disponível em: E/CN.4/RES/1991/25, https://www. refworld.org/docid/3b00fOblc.html.

VANDRESEn, Thaís e AnTunes DE SOUZA, Maria Cláudia S., "Globalization, Global Governance, and Challenges to Contemporary Constitutionalism: The (trans) Constitutional Respective and the Dialogue among Jurisdictions", University of Baltimore Journal of International Law, Baltimore, vol. 4, núm. 2, art. 2, 2015-2016.

WeILER, J. H. H., “The Geology of International Law. Governance, Democracy and Legitimacy", Zeitschrift für Ausländisches Öffentliches Recht und Völkerrecht, Heidelberg, vol. 64, 2004.

Williamson, Richard L. Jr., "Hard Law, Soft Law and Non-Law in Multilateral Arms Control: Some Compliance Hypotheses", Chicago Journal of International Law, Chicago, vol. 4, núm. 1, art. 7, abril de 2003. 